\title{
Analysis of Cerebellar Development in math1 Null Embryos and Chimeras
}

\author{
Patricia Jensen, ${ }^{1}$ Richard Smeyne, ${ }^{2}$ and Dan Goldowitz ${ }^{1}$ \\ ${ }^{1}$ University of Tennessee Health Science Center, Memphis, Tennessee 38163, and 2Department of Developmental Neurobiology, St. Jude Children's \\ Research Hospital, Memphis, Tennessee 38105
}

\begin{abstract}
The cerebellar granule cell is the most numerous neuron in the nervous system and likely the source of the most common childhood brain tumor, medulloblastoma. The earliest known gene to be expressed in the development of these cells is math1. In the math1 null mouse, neuroblasts never populate the external germinal layer (EGL) that gives rise to granule cells. In this study, we examined the embryonic development of the math 1 null cerebellum and analyzed experimental mouse chimeras made from math 1 null embryos. We find that the anterior rhombic lip gives rise to more than one cell type, indicating that the rhombic lip does not consist of a homogeneous population of cells. Furthermore, we demonstrate that math 1 null granule cells are absent in the math1 null chimeric cerebellum, from the onset of their genesis in the mouse anterior rhombic lip. This finding indicates a vital cell intrinsic role for Math 1 in the granule cell lineage. In addition, we show that wild-type cells are unable to compensate for the loss of mutant cells. Finally, the colonization of the EGL by wild-type cells and the presence of acellular gaps provides evidence that EGL neuroblasts undergo active migration and likely have a predetermined spatial address in the rhombic lip.
\end{abstract}

Key words: granule cell; rhombic lip; EGL; migration; Purkinje cell; foliation

\section{Introduction}

The anterior rhombic lip (ARL) of the developing cerebellum gives rise to the most numerous cell in the adult brain, the granule cell. In the mouse, the ARL is discernible by embryonic day (E) 9 , and by E13, granule cell neuroblasts from the ARL begin to migrate over the surface of the cerebellar anlagen to populate the external germinal layer (EGL) (Miale and Sidman, 1961). The earliest known marker of these cells is the basic helix-loop-helix transcription factor Math1 (Akazawa et al., 1995; Ben-Arie et al., 1996, 1997, 2000; Helms and Johnson, 1998). In the math1 null mutant, the EGL fails to form (Ben-Arie et al., 1997), indicating that Math1 is a critical factor for the progression of the granule cell lineage. To determine the autonomy of Math1 in granule cell development and to gain insights into granule cell lineage and migration in the formation of the mouse cerebellum, we have analyzed the effects of the math 1 null mutation on embryonic ARL development and on postnatal cerebellar development using experimental mouse chimeras.

We find that in the embryonic ARL of the mouse, there are at least two populations of cells: a Math1-dependent population

Received July 21, 2003; revised Jan. 9, 2004; accepted Jan. 14, 2004

This work was supported by a University of Tennessee Health Science Center, Center for Neuroscience Fellowship (P.J.) and grants from the Human Frontiers Science Program (D.G.) and the American Lebanese Syrian Associated Charities (R.S.). We gratefully acknowledge Huda Zoghbi (Baylor College of Medicine, Houston, TX) for the math1 null mice. We thank Richard Cushing and Meifen Lu for technical assistance.

Correspondence should be addressed to Dr. Dan Goldowitz, Department of Anatomy and Neurobiology, University of Tennessee Health Science Center, 855 Monroe Avenue, Memphis, TN 38163. E-mail: dgold@nb.utmem.edu.

P. Jensen's present address: Department of Developmental Neurobiology, St. Jude Children's Research Hospital, Memphis, TN 38105.

DOI:10.1523/JNEUROSCI.3427-03.2004

Copyright $\odot 2004$ Society for Neuroscience $\quad$ 0270-6474/04/242202-10\$15.00/0 and a Math1-independent population. We identify a population of Math1-positive cells in the math1 null that are not granule cell neuroblasts and that appear to be Math1 independent as they survive in the mutant. These findings provide evidence that the cells in the ARL do not compose a homogeneous population.

In the math 1 null chimeric cerebellum, only wild-type cells populate the EGL, indicating a vital, cell-intrinsic role for Math1 in the development of the granule cell lineage. In addition, wildtype granule cell neuroblasts do not appreciably compensate for the absence of mutant cells. Interestingly, the lack of compensation by wild-type granule cells creates regions in the mutant chimeric cerebellum that completely lack an EGL, and, in some cases, these regions are noncontiguous. This finding suggests that the formation of the EGL is an active process of cells leaving the ARL to populate the EGL.

\section{Materials and Methods}

Animals and determination of genotype. The heterozygous math1 null mouse $\left(\right.$ math $\left.1^{\beta-G a l /+}\right)$, which contains a $\beta$-galactosidase $(\beta$-gal) reporter gene (lacZ) in place of the math 1 open reading frame, was obtained from Dr. Huda Y. Zoghbi (Baylor College of Medicine, Houston, TX) (Bermingham et al., 1999). All mice used in this study were maintained at the University of Tennessee Health Science Center animal care facility. Mice were kept on a 14/10 hr light/dark cycle with food and water ad libitum. All of the mice were treated in accordance with Society for Neuroscience policy on the use of animals in research under a locally approved animal care protocol.

Because math $1^{\beta-G a l / \beta-G a l}$ mice are neonatal lethal, all math $1^{\beta-G a l / \beta-G a l}$ and $m a t h 1^{+/+}$mice used in this study were generated from matings between math $^{\beta-G a l /+}$ breeding pairs. Females were examined each morning for the presence of a vaginal plug. Once a plug was detected, the female was removed from the male, and noon of that day was designated 
as E0.5. Embryos were collected on E10.5, 11.5, 12.5, 13.5, 15.5, 17.5, and 18.5 and the day of birth (P0). To determine genotype, DNA was isolated from either the tail or yolk sac. The math1 genotype was determined by PCR, as described previously (Jensen et al., 2002).

Tissue preparation. Mice E17.5 or older were anesthetized with Avertin and perfused transcardially with a $0.1 \mathrm{M}$ PBS solution, $\mathrm{pH} 7.3$, followed by fixation with either $4 \%$ paraformaldehyde or a 3:1 solution of $95 \%$ ethanol and acetic acid (EtOH:AA). Mice younger than E17.5 were immersion fixed in either 4\% paraformaldehyde or EtOH:AA. Paraformaldehyde-fixed tissue was rinsed with PBS and cryoprotected overnight in a $30 \%$ sucrose in PBS solution. Tissue was embedded in tissue-freezing medium (TBS; Triangle Biomedical Sciences, Durham, $\mathrm{NC}$ ), and $20 \mu \mathrm{m}$ sagittal cryosections were mounted on Superfrost Plus slides (Fisher Scientific, Pittsburgh, PA). EtOH:AA-fixed tissue was placed in $70 \%$ ethanol overnight, followed by dehydration in a series of ethanols and clearing in xylenes. Tissue was embedded in paraffin, and 6 $\mu \mathrm{m}$ sagittal sections were mounted on Superfrost Plus slides (Fisher Scientific).

Detection of proliferation in the rhombic lip. To examine cell proliferation in the ARL, timed pregnant dams were injected intraperitoneally with 5-bromo-deoxyuridine (BrdU; $50 \mu \mathrm{g} / \mathrm{g}$ body weight) at E13.0 or 1 hr before the collection of embryos. Embryos were examined at E13.5, $15.5,17.5$, or 18.5. Tissue was processed for paraffin embedding and sectioned as described above. Sections were cleared in xylenes, rehydrated with decreasing concentrations of ethanol, and rinsed in distilled $\mathrm{H}_{2} \mathrm{O}\left(\mathrm{dH}_{2} \mathrm{O}\right)$. For each time point, one set of slides was stained with cresyl violet and examined for the presence of mitotic figures. A second set of slides was processed for BrdU immunohistochemistry. For BrdU immunohistochemistry, slides were pretreated with $1 \mathrm{~N} \mathrm{HCl}$ at $37^{\circ} \mathrm{C}$ for 30 min, followed by PBS containing $0.3 \%$ Triton X-100 (PBS/T) rinse and incubation with an antibody against BrdU (anti-G4G3; 1:4; Developmental Studies Hybridoma Bank) overnight at room temperature. The following day, slides were further processed according to the immunohistochemisty protocol described below using the ABC Elite detection system (Vector Laboratories, Burlingame, CA). To quantify the number of BrdU-positive cells, five sagittal sections equally distributed across 480 $\mu \mathrm{m}$ were counted using $100 \times$ objective from the E15.5 ARL $(n=2$ math $1^{\beta-G a l / \beta-G a l}$ and $n=2$ math $\left.1^{+/+}\right)$. In addition, counts of the interior face and exterior face of math $1^{+/+}$ARL were determined. The total number of BrdU-positive cells was estimated using the formula of Konigsmark (1970).

Detection of cell death in the rhombic lip. To examine cell death in the ARL at E13.5, 15.5, and 17.5 and P0, paraformaldehyde-fixed and paraffin-embedded sections were cleared in xylenes, rehydrated with decreasing concentrations of ethanol, and rinsed in $\mathrm{dH}_{2} \mathrm{O}$. For each time point, one set of slides was stained with cresyl violet and examined for dead or dying cells as evidenced by the presence of pyknotic nuclei. A second set of slides was processed for terminal deoxynucleotidyl transferase (TdT)-mediated dUTP nick end labeling (TUNEL) assay using the DeadEnd Colorimetric Apoptosis Detection System (Promega, Madison, WI) according to the manufacturer's instructions, with the following modifications: sections were permeabilized with $100 \mu \mathrm{g} / \mathrm{ml}$ proteinase $\mathrm{K}$, and TdT reaction mix was made using $0.5 \mu \mathrm{l}$ of TdT per slide.

$\beta$-gal immunohistochmistry and detection of $\beta$-gal activity. To examine Math1/lacZ expression, we performed $\beta$-gal immunohistochemistry and 5-bromo-4-chloro-3-indolyl- $\beta$-D-galactoside (X-gal) reaction for $\beta$-gal activity. For $\beta$-gal immunohistochemistry, EtOH:AA-fixed paraffin sections were cleared in xylenes and rehydrated with graded ethanols. After antigen retrieval using the protocol of Jiao et al. (1999), slides were rinsed in PBS/T and blocked, and sections were incubated with antibodies against $\beta$-gal (1:50; Biogenesis, Sandown, $\mathrm{NH}$ ) overnight at room temperature. Slides were rinsed with PBS/T and incubated with Alexa 594 secondary antibody (1:2000; Molecular Probes, Eugene, OR) for $30 \mathrm{~min}$ at room temperature.

For detection of $\beta$-gal activity, $4 \%$ paraformaldehyde-fixed embryos or cryosections were rinsed in PBS/T and then incubated at $30-35^{\circ} \mathrm{C}$ overnight in an X-gal (Roche, Nutley, NJ) mix in $0.1 \mathrm{M} \mathrm{PBS} / \mathrm{T}$ containing $5 \mathrm{~mm}$ potassium ferricyanide, $5 \mathrm{~mm}$ ferrocyanide, $2 \mathrm{~mm} \mathrm{MgCl}_{2}, 0.02 \%$ $\mathrm{NP}-40,0.01 \%$ sodium deoxyxcholate, and $1 \mathrm{mg} / \mathrm{ml} \mathrm{X}$-gal dissolved in
DMSO. After incubation, tissue was rinsed with $0.1 \mathrm{~m}$ phosphate buffer. Embryos were processed for paraffin embedding and sectioned as described above. All tissue processed for X-gal activity was counterstained with neutral red.

Generation of experimental murine chimeras. Because of the neonatal lethality of homozygous math1 null mice $\left(\right.$ math $\left.1^{\beta-G a l / \beta-G a l}\right)$, the mutant component of the chimeras was generated by mating math $1^{\beta-G a l /+}$ males and females to generate math $1^{\beta-G a l / \beta-G a l}$, math $1^{\beta-G a l /+}$, or $m a t h 1^{+/+}$embryos. The wild-type $(+/+)$ component was generated from one of five different lines: ICR, Rosa26 (Friedrich and Soriano, 1991), Balb/c J , GTO (Lo et al., 1987), or math $1^{+/+}$. Experimental mouse chimeras were generated as described previously (Goldowitz and Mullen, 1982; Goldowitz, 1989). In brief, four- to eight-cell math $1^{\beta-G a l / \beta-G a l}$, math $1^{\beta-G a l /+}$, or math $1^{+/+}$, and $+/+$embryos were cultured together overnight. After successful fusion, blastocysts were transplanted into the uterine horn of pseudo-pregnant host ICR females.

Chimeras and $+/+$ controls were collected at P0, 5, 12, and 21. Animals were anesthetized deeply with Avertin, and tail biopsies were taken for detection of the presence of Math1/lacZ-positive cells (Jensen et al., 2002). Then, mice were perfused transcardially with a $0.1 \mathrm{M}$ PBS, followed by fixation with EtOH:AA, paraformaldehyde-lysine-periodate (PLP) at pH6.2, or 4\% paraformaldehyde. EtOH:AA-fixed tissue was embedded in paraffin, and $6 \mu \mathrm{m}$ sections were mounted on Superfrost Plus slides. PLP- and paraformaldehyde-fixed tissue was rinsed with PBS and stored at $4^{\circ} \mathrm{C}$ until further processing.

Identification of genotypically Math1/lacZ cells. Two different techniques were used to determine the presence of genotypically Math1/lac $Z$ cells. For EtOH:AA-fixed and paraffin-embedded brains, sections were processed for $\beta$-gal immunohistochemistry as described above. For PLPand paraformaldehyde-fixed tissue, whole brains or cryosections were reacted for $\beta$-gal activity as described above. Whole brains were processed for paraffin embedding and sectioned as described above. Both cryo and paraffin sections reacted for X-gal were counterstained with neutral red.

Identification of genotypically wild-type cells. In P0, 5, and 12 math $1 \leftrightarrow$ GTO chimeras, genetically GTO, wild-type cells were identified by the presence of the globin transgene using DNA in situ hybridization (Hamre and Goldowitz, 1997). Probes for the transgene were labeled with biotinylated dUTP (Enzo Biochem, New York, NY) by nick translation protocol according to Rigby et al. (1977). Sections were deparaffinized with xylenes, rinsed in $100 \%$ ethanol, denatured in $2 \times \mathrm{SSC}(300 \mathrm{~mm} \mathrm{NaCl}$ and $30 \mathrm{~mm}$ sodium citrate, $\mathrm{pH} 7.5$ ) at $80^{\circ} \mathrm{C}$ for $10 \mathrm{~min}$, and dehydrated in an ascending series of ethanols. Sections were hybridized with biotinylated probe $(10 \mathrm{ng} / \mu \mathrm{l})$ in $2.5 \times \mathrm{SSC}, 10 \%$ dextran sulfate, and salmon sperm DNA $(25 \mathrm{ng} / \mu \mathrm{l})$ overnight at $56^{\circ} \mathrm{C}$. Sections were rinsed with $2 \times, 1 \times$, and $0.1 \times$ SSC, and labeled cells were visualized by alkaline phosphatase histochemistry using the chromogen nitro-blue tetrazolium and substrate 5-bromo-4-chloro-3-indolyl phosphate. GTO cells were identified by the presence of a blue-black to purple precipitate in their nucleus.

Estimation of chimerism and three-dimensional reconstruction of chimeric cerebella. To estimate chimerism, we measured the area of the EGL in P0 and P5 chimeric and control cerebella. For each brain, three nonconsecutive sagittal sections were analyzed and averaged. The EGL and cerebellar area were traced and calculated using AnalySIS Opit 3.1 imaging system (Soft Imaging System Corp., Lakewood, CO). The ratio of chimeric to wild-type areas provided an estimation of chimerism, although it must be realized that this measure is simply a reporter of a diminished granule cell population and very small disruptions of the EGL may not be detected using this approach (see Results).

For three-dimensional reconstruction, brains were sectioned in the sagittal plane, mounted onto slides, and Nissl stained. At $75 \mu \mathrm{m}$ intervals, images of sections from the midline toward the hemisphere were captured at $2.5 \times$ using the Bioquant image analysis system (Bioquant NOVA; R \& M Biometrics, Nashville, TN). Using the captured images as a template, the individual outlines of the cerebellum, EGL alone, and agranular EGL alone were manually traced for each section. Each of the individual sections was then placed into a composite file and aligned in the $x$ - and $y$-axis based on computer-generated landmarks. Threedimensional reconstructions were generated using a three dimensional 
model generator in Bioquant. Bitmapped files from Bioquant were imported into Adobe Photoshop (version 7.0; Adobe), where they were labeled and composed into a single figure.

Immunohistochemistry. Slides were rinsed in PBS/T, blocked with 3\% BSA, and incubated overnight at room temperature with one or more of the following antibodies: rabbit anti-calbindin (Chemicon, Temecula, CA), goat anti- $\beta$-gal (Biogenesis), mouse anti-NeuN (Chemicon), and rabbit anti-GFAP (Shandon-Lipshaw, Pittsburgh, PA). The following day, slides incubated with anti-calbindin were rinsed with $\mathrm{PBS} / \mathrm{T}$ and incubated with a biotinylated secondary antibody (1:200) for $30 \mathrm{~min}$ at room temperature, and immunoreactivity was detected with $\mathrm{DAB}$ using the $\mathrm{ABC}$ Elite kit according to the manufacturer's instructions. For all other antibodies, slides were rinsed with $\mathrm{PBS} / \mathrm{T}$ and incubated with the appropriate secondary antibody (Alexa 594 donkey anti-goat, Alexa 488 goat anti-mouse, or Alexa 350 goat anti-rabbit; 1:2000; Molecular Probes) for $30 \mathrm{~min}$ at room temperature. For triple-labeling experiments, slides were first incubated with Alexa 594 donkey anti-goat for 30 min, rinsed thoroughly with PBS/T, followed by incubation with both Alexa 488 goat anti-mouse and Alexa 350 goat anti-rabbit for an additional $30 \mathrm{~min}$. After rinsing, slides were coverslipped with Vectashield Mounting Medium (Vector Laboratories). As a control, known $\beta$-galpositive and -negative tissue was processed with experimental tissue. Additional controls included the exclusion of the primary antibodies. For triple-labeling experiments, we included a slide incubated with goat anti$\beta$-gal primary and all three secondary antibodies, as described above, to control for possible cross-reactivity between the secondary antibodies raised in goat and the $\beta$-gal antibody. No cross-reactivity was evident. Fluorescent images were captured on a LSM 510 Meta multiphoton microscope (Zeiss, Oberkochen, Germany).

\section{Results}

\section{Analysis of the math 1 null cerebellum}

In the developing cerebellum, Math1 is expressed in the cells of the ARL and granule cell neuroblasts in the EGL (Helms and Johnson, 1998, 2000). In the absence of math1, the ARL is greatly reduced in size, and the EGL does not form (Fig. $1 A, C, E$ ) (BenArie et al., 1997, 2000). To gain insight into the role of math1 in granule cell development, we performed a more detailed analysis of the development of the math 1 null cerebellum. We examined the effects of the math1 null mutation on ARL development at E13.5, 15.5, 17.5, and 18.5 and P0. In the mouse, granule cell neuroblasts are generated in the ARL and begin migrating over the surface of the cerebellum on approximately E13 (Miale and Sidman, 1961). In the math $1^{\beta-G a l / \beta-G a l}$ cerebellum, the absence of the EGL was apparent at E13.5 (Fig. 1A). At this time, there was no obvious difference in the size of the ARL (Fig. $1 A, B$ ). However, by E15.5 the math $1^{\beta-\text { Gal } / \beta \text {-Gal }}$ ARL was noticeably reduced in size compared with the wild-type cerebellum (Figs. 1C,D, 2A, B). The ARL, according to Altman and Bayer (1997), is divided into two epithelial linings or faces: the interior face, adjacent to the fourth ventricle and continuous with the ventricular neuroepithelium, and an exterior face that is continuous with the EGL. In the math $1^{\beta-G a l / \beta-G a l}$ ARL, by definition and cytoarchitecture (i.e., the interior face has a columnar organization similar to the neuroepithelium, whereas the exterior face is more tangentially organized like the EGL), the exterior face appears to be absent (Fig. 1 , compare $C, D, 2$, compare $A, B$; see figure legend). There were no differences observed between the wild-type and math $1^{\beta \text {-Gal/+ }}$ cerebellum at all ages examined.

To determine whether the reduction in ARL size was attributable to the absence of cell proliferation, we examined cresyl violet-stained sections for the presence of mitotic figures. At all ages examined, mitotic figures were present within the math $1^{\beta-G a l / \beta-G a l}$ ARL (Fig. 2A, E15.5 ARL). BrdU labeling confirmed the presence of proliferating cells at all time points in the math $1^{\beta-G a l / \beta-G a l}$ cerebellum (Fig. 2C, E15.5 ARL). Quantitative

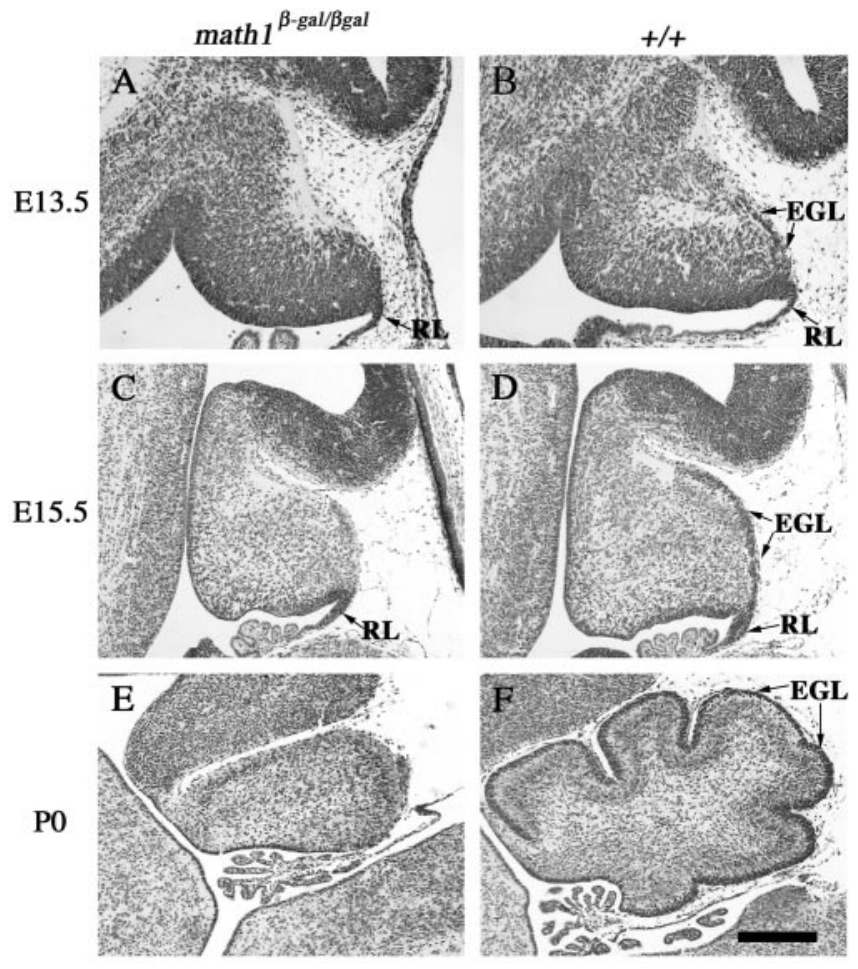

Figure 1. Analysis of the $m a t h 1^{\beta-G a l / \beta-G a l}$ cerebellum. Sagittal view of $m a t h 1^{\beta-G a l / \beta-G a l}(A$, $C, E)$ and $+/+(B, D, F)$ cerebella stained with cresyl violet. $A, C, E$, The EGL is absent in all math $^{\beta}{ }^{\beta-\text { Gal/ } \beta \text {-Gal }}$ cerebella. However, at E13.5, there is no apparent size difference between the math ${ }^{\beta-\text { Gal/ } \beta \text {-Gal }}(A)$ and $+/+(B)$ cerebellum. By E15, the math $1^{\beta-\text { Gal } \beta \text {-Gal }}$ cerebellum $(C)$ and rhombic lip (RL) is noticeably smaller than the $+/+$ littermate $(D)$. By P0, the difference in cerebellar size is even more pronounced because of the absence of foliation in the math $7^{\beta-\text {-Gal } \beta \text {-Gal }}$ cerebellum (E) compared with the $+/+$ littermate (F). Scale bar, $200 \mu \mathrm{m}$.

analysis of BrdU-positive cells in the E15.5 math $1^{\beta-G a l / \beta-G a l}$ and wild-type ARL demonstrated an increased number of BrdU cells in the wild-type brain ( 5152 and 5488 cells in the wild-type ARL compared with 3136 and 3328 cells in the mutant ARL; see Materials and Methods for details of counts). Interestingly, there was no difference in the number of BrdU-positive cells between E15.5 math $1^{\beta-\text { Gal } \beta \text {-Gal }}$ ARL (3136 and 3328) and the interior face of the wild-type ARL (3152 and 3312). These findings are consistent with the loss of the exterior face of the ARL in the mutant cerebellum.

To determine whether the diminution of the mutant ARL over time was attributable to cell death, we examined cresyl violetstained sections for pyknotic nuclei and TUNEL, hallmarks of dying cells. At E15.5, we rarely observed pyknotic nuclei in the ARL of math $1^{\beta-G a l / \beta-G a l}$ cerebella (in only one of four mutant cerebellum). There was also no obvious cell death at later time points. To examine this further, we performed TUNEL staining. We found no TUNEL-positive cells in either the $m a t h 1^{\beta-G a l / \beta-G a l}$, math $1^{\beta-G a l /+}$, or wild-type ARL at any age examined (Fig. $2 E$, E15.5 ARL). Thus, cell death does not seem to be the basis for the reduced sized of the math $1^{\beta-G a l / \beta-G a l}$ ARL.

One possible explanation for the progressive reduction in ARL size over time is that cells are migrating away from this region. To examine this, we looked at Math1/lacZ expression from E10.5 to $\mathrm{P} 0$ in the math $1^{\beta-G a l / \beta-G a l}$ and math $1^{\beta-G a l /+}$ cerebellum. It has previously been demonstrated that the expression pattern of lacZ in math $1^{\beta-G a l / \beta-G a l}$ mice replicates the known expression pattern of Math1 in the cerebellum (Ben-Arie et al., 2000). At all ages examined, Math1/lacZ-positive cells were seen 

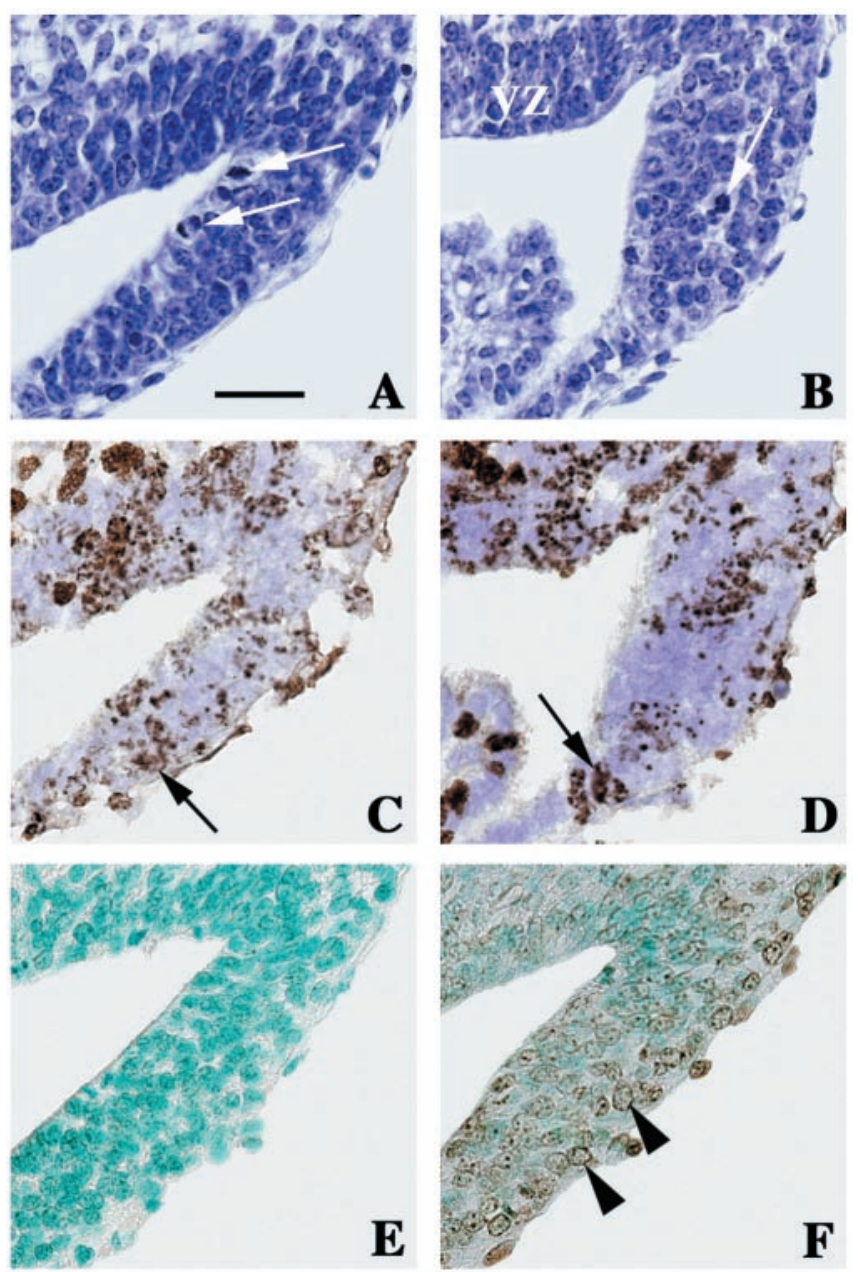

Figure 2. Normal cell proliferation and absence of cell death in the E15.5 math $1^{\beta-G a l / \beta-G a l}$ rhombic lip. Sagittal view of E15.5 math $1^{\beta-G a l / \beta-G a l}(A, C, E, F)$ and E15.5 $+/+(B, D)$ rhombic lip, with the ventricular zone (VZ) at the top left of each image. $A, B$, Cresyl violet-stained sections demonstrating the presence of mitotic figures (white arrows) in both the math $1^{\beta-G a l / \beta \text {-Gal }}(A)$ and $+/+(B)$ rhombic lip. In $B$, the arrow also demarcates the interior face (left) and the exterior face (right) of the rhombic lip. In ( and D, BrdU was injected atE12.5. The presence of BrdU-positive cells (black arrows) confirms that there is active proliferation in both the math $1^{\beta-\text { Gal/ } \beta \text { - }}$ Gal ( $C$ and $+/+(D)$ rhombic lip. E, F, TUNEL assay for apoptotic cell death reveals no cell death in the math $^{\beta-G a l / \beta \text {-Gal }}$ rhombic lip (E) compared with the TUNEL-positive cells (arrowheads) in the DNasetreated positive control $(F)$. Scale bar, $30 \mu \mathrm{m}$.

within the ARL of the math $1^{\beta-G a l / \beta-G a l}$ and the math $1^{\beta-G a l /+}$ cerebellum (Fig. 3). Between E10.5 and the onset of EGL formation at E13.5, we observed a population of cells emanating from the ARL that was Math1/lacZ positive in both the math $1^{\beta-G a l / \beta-G a l}$ and $m a t h 1^{\beta-G a l /+}$ cerebellum. The Math1/lacZ-positive cells appeared to be migrating from the interior face of the ARL toward the surface of the cerebellum and then rostrally over the cerebellum in a subpial manner (Fig. 3B). At later time points, some of these cells were found deep to the pia that suggested they were descending into the cerebellar plate in both the math $1^{\beta-G a l / \beta-G a l}$ (Fig. $3 B, C$ ) and math $1^{\beta-G a l /+}$ cerebellum. Our findings demonstrate that before E13.5 in the mouse cerebellum, the ARL is composed of at least two different cell types. There is a Math1dependent population (those cells that will populate the EGL and are absent in the mutant) and a Math1-independent population of cells (the second Math1/lacZ-positive cell population that survive in the mutant).

\section{Analysis of math $1^{\beta-G a l / \beta-G a l}$ chimeras}

To examine possible effects that wild-type cells might confer on math1 null mutant cells, as well as the effects of the math1 null mutation on cerebellar development beyond P0, we generated experimental mouse chimeras by the aggregation of wild-type embryos with embryos produced from heterozygous math $1^{\beta-G a l /+}$ matings. Chimeric cerebella were analyzed at P0, 5, 12, and P21. As an initial determination of $m a t h 1^{\beta-G a l / \beta-G a l}$ genotype, we examined chimeras for the characteristic signs of the math $1^{\beta-G a l / \beta-G a l}$ mutant phenotype: the absence of foliation and incomplete fusion at the midline (Ben-Arie et al., 1997; Jensen et al., 2002).

At all ages examined, the presence of a math $^{\beta-G a l / \beta-G a l} \mathrm{com}-$ ponent to the chimeric cerebellum was immediately apparent by the presence of abnormal foliation. Of the 103 chimeras examined, 29 had abnormal foliation (Table 1). There was considerable variation in the foliation pattern of the 29 cerebella suspected to be from $m a t h 1^{\beta-G a l / \beta-G a l} \leftrightarrow+/+$ chimeras, ranging from what appeared to be complete lack of foliation to almost normal foliation and, in some cases, hyper-foliation. From a gross observation, there appeared to be no consistency to the patterning defect in either the mediolateral or anteroposterior axis. However, in all cerebella with diminished foliation at the vermis, there also appeared to be incomplete fusion at the midline.

To confirm the foliation defects, cerebella were sectioned in either the sagittal or coronal plane and stained for cresyl violet or neutral red. Nine of the 36 P0 cerebella and 8 of the 27 P5 cerebella were suspected of containing a mutant component based on abnormal gross morphology (Table 1). In the normal P0 cerebellum, a four- to six-cell-thick EGL covers the entire surface of the cerebellum, and the primary fissures are apparent (Fig. 4A). By $\mathrm{P} 5$, the normal cerebellum has doubled in size, the EGL is six to eight cells thick, there is active inward migration of granule cells, and foliation is more pronounced compared with the P0 cerebellum (Fig. 5D). In P0 and P5 presumed math $1^{\beta-G a l / \beta-G a l} \leftrightarrow+/+$ cerebella, regions of the EGL were completely lacking (Fig. $4 B, C, E, F)$. In some cases, only the most anterior or posterior portion of the EGL was absent. However, in some of the math $1^{\beta-G a l / \beta-G a l} \leftrightarrow+/+$ cerebella there were noncontiguous regions of missing EGL (Figs. $4 F, 5 D$ ). In all regions of these cerebella lacking an EGL, or directly adjacent to gaps in the EGL, foliation was disrupted. Where there were large gaps in the EGL, foliation was completely absent (Fig. $4 B$ ). In some instances, in regions adjacent to gaps in the EGL, there was hyperextension of a lobule (Fig. $4 B, E$ ).

To better assess the global patterns of EGL abnormalities, we performed a three-dimensional reconstruction on two P0 and three P5 mutant chimeras (see Materials and Methods). The regions lacking EGL had orientations in both the mediolateral and anterioposterior dimensions (Fig. 5A-D). In all five chimeras analyzed in this manner, there was little evidence of spotty omissions of granule cells; rather, these agranular regions of the EGL occurred in large clusters in either the anterioposterior or mediolateral dimensions, suggesting a coherent clonal allocation of presumptive Math1-null cells.

We then examined 18 P12 and 22 P21 chimeras to assess how the defects in the EGL affect the progression of cerebellar development. Five of the 18 P12 cerebella and 7of the 22 P21 cerebella were suspected of containing a mutant component based on gross morphology (Table 1). By P12 in the normal cerebellum, the EGL is only three to four cells thick, there is active inward migration of granule cells, a well established internal granule cell layer (IGL), and the secondary fissures are present (Fig. 6A). By $\mathrm{P} 21$, the EGL is no longer present, and the IGL is fully formed (Fig. 6D). In the $12 \mathrm{P} 12$ and P21 suspected math $1^{\beta-G a l / \beta-G a l} \leftrightarrow+/+$ 
chimeras, disruptions in foliation were confirmed. As we saw with the P0 and P5 chimeras, the extent of the disruption was greatly varied. However, the overall disruption of the cerebellum appeared even more pronounced in the older chimeras (Fig. 6 $B, C, E, F)$. In some cases, folia appeared to have collapsed, resulting in a folding over of the cerebellar cortex (Fig. $6 B, E)$. The variable foliation phenotypes in the math1 null chimeric cerebella appear to be the result of two factors: the location of the acellular regions and the extent of the acellular region (Chen and Hillman, 1988). If, for example, the acellular region is located at the base of a folia, there is a lengthening of the folia (Figs.

$4 B, E, 5 B)$. However, if the acellular region occurs between two areas of rapid growth there is shortening of the folia (Figs. $4 F$, $5 C)$. Thus, numerous gaps along the EGL (as in some of our chimeras or the methylazoxymethanol acetate (MAM)-treated cerebella of Chen and Hillman (1988)] would produce an overall decrease in the growth of the EGL and an increase in the number of fissures produced that are shorter than normal (Fig. $6 F$ ). The size of these gaps is also important. Gaps encompassing an entire lobe of the cerebellum result in no foliation (Fig. $4 B, 6 B, C$ ). Thus, these studies provide a dramatic illustration of the important role that the EGL plays in cerebellar foliation. Although the EGL is necessary for the complete fusion of the cerebellar anlagen (Jensen et al., 2002), in three chimeras (one at P12 and two at P21) with virtually no granule cells in the vermis there was at least a partial fusion at the midline (see Fig. $10 \mathrm{~B}$ ), indicating that the granule cells do not appear to be necessary for the initial fusion of the two lateral cerebellar anlagen. This is consistent with the recent findings of Louvi et al. (2003). Finally, the two sides of the cerebellum seemed to be equally affected in all chimeras examined (Figs. 6F, 10 B).

\section{Identification of genotype and estimation of chimerism}

To determine the genotypic composition of chimeras, PCR genotyping of tails was performed, and all brains were histochemically reacted for the presence of lacZ-positive cells (see Materials and Methods). Of the 29 chimeras presumed to contain a mutant component based on gross phenotype, none contained lacZpositive granule cells, and all were PCR positive for lacZ. The absence of lacZ-positive granule cells in chimeras is identical with the observation of no lacZ-positive granule cells in the math1 null cerebellum (Ben-Arie et al., 2000). LacZ-positive cells were, however, present in other regions of chimeric brains (Ben-Arie et al., 2000). Thus, the 29 chimeras suspected of being derived from a math1 null embryo based on phenotypic consideration were shown by $\beta$-gal histochemistry to contain math 1 null cells. The proportion of homozygous mutant chimeras (29 of 103) was expected from the mating scheme used to produce the math1 component of chimeras. It should be noted that we may have missed very low percentage mutant chimeras with this approach.

In math $1^{\beta-G a l / \beta \text {-Gal }} \leftrightarrow+/+\mathrm{P} 0$ chimeras, lacZ-positive cells were evident within the medullary vellum and choroid plexus, but mutant cells did not colonize the EGL (Fig. $7 A, B$ ). In math $1^{\beta-G a l / \beta-G a l}$ and $m a t h 1^{\beta-G a l /+}$ chimeras, a population of lac Zpositive cells was also detected within the white matter and forming cerebellar plate at P0 (Fig. $7 B, D$ ). At later time points, large cells within the IGL (apparent Golgi type II based on size and
Table 1. Summary of chimeras generated noting age, wild-type genotype, and mutant phenotype

\begin{tabular}{|c|c|c|c|}
\hline Age & $\begin{array}{l}\text { Chimeras (math1 } \leftrightarrow \text { wild } \\
\text { type) }\end{array}$ & $\begin{array}{l}\text { Total number } \\
\text { of chimeras } \\
\text { generated }\end{array}$ & $\begin{array}{l}\text { Number of chimeras } \\
\text { with abnormal } \\
\text { cerebellar phenotype }\end{array}$ \\
\hline PO & math $1 \leftrightarrow B A L B / c$ & 12 & 2 \\
\hline PO & math $1 \leftrightarrow$ math $1^{+/+}$ & 13 & 4 \\
\hline PO & math $1 \leftrightarrow \mathrm{GTO}$ & 11 & 3 \\
\hline P5 & math1 $\leftrightarrow \mid C R$ & 22 & 5 \\
\hline P5 & math1 $\leftrightarrow$ GTO & 5 & 3 \\
\hline P12 & math $1 \leftrightarrow$ math $1^{+/+}$ & 4 & 1 \\
\hline P12 & math $1 \leftrightarrow B A L B / c$ & 8 & 2 \\
\hline P12 & math1 $\leftrightarrow$ GT0 & 6 & 2 \\
\hline P21 & math1 $\leftrightarrow B A L B / C$ & 10 & 3 \\
\hline P21 & math $1 \leftrightarrow$ ROSA26 & 12 & 4 \\
\hline Total & & 103 & 29 \\
\hline
\end{tabular}

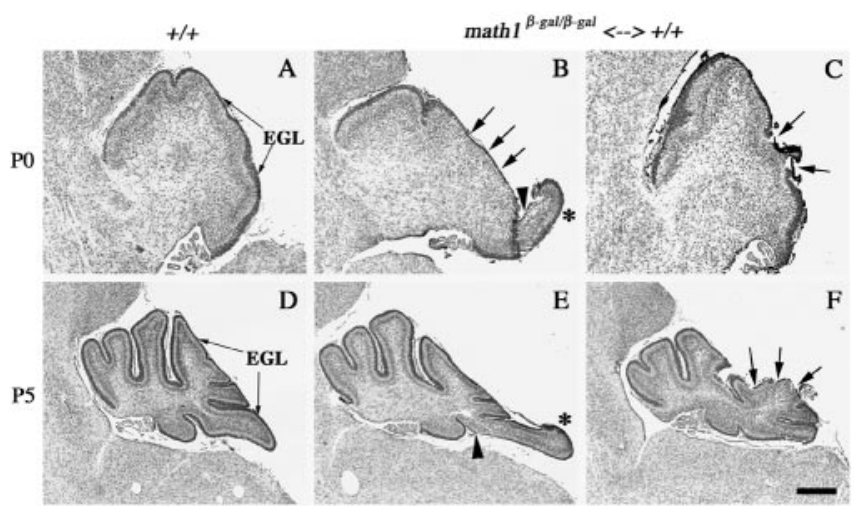

Figure 4. $\quad$ math $1^{\beta-G a l / \beta-G a l} \leftrightarrow+/+$ chimeras demonstrate an abnormal EGL with associated abnormalities in foliation. Sagittal view of $\mathrm{PO}+/+(A)$ and $m a t h 1^{\beta-G a l / \beta-G a l}<->$ $+/+(B, C)$ lateral cerebella and $P 5+/+(D)$ and math $1^{\beta-G a l / \beta-G a l}<->+/+(E, F)$ medial cerebella stained with cresyl violet. $B, C, E, F$, In all chimeric cerebella, there are regions of the EGL that are severely disrupted or absent (arrows and arrowheads). Where there are gaps in the EGL, foliation is disrupted compared with wild-type cerebella in $A$ and $D$. Where there are large gaps in the EGL, as seen in $B$ (arrows), foliation is absent. In some cases, where the EGL is present near the base of a folia ( $B, E$, arrowheads), there is hyperextension of that folia (asterisk). The dark lining of the cerebellum in $B$ and $C$, which has acellular areas opposite the arrows, is attributable to India ink used to highlight the gross cerebellar abnormalities in the unsectioned brain. Scale bar: $A-C, 150 \mu \mathrm{m} ; D-F, 300 \mu \mathrm{m}$.

location), smaller cells adjacent to Purkinje neurons (presumed Bergmann glia), and cells within the molecular layer were also Math1/lacZ positive (Fig. 7E). Using a neuronal (anti-NeuN) and a glial (anti-GFAP) marker, we examined the phenotype of these 

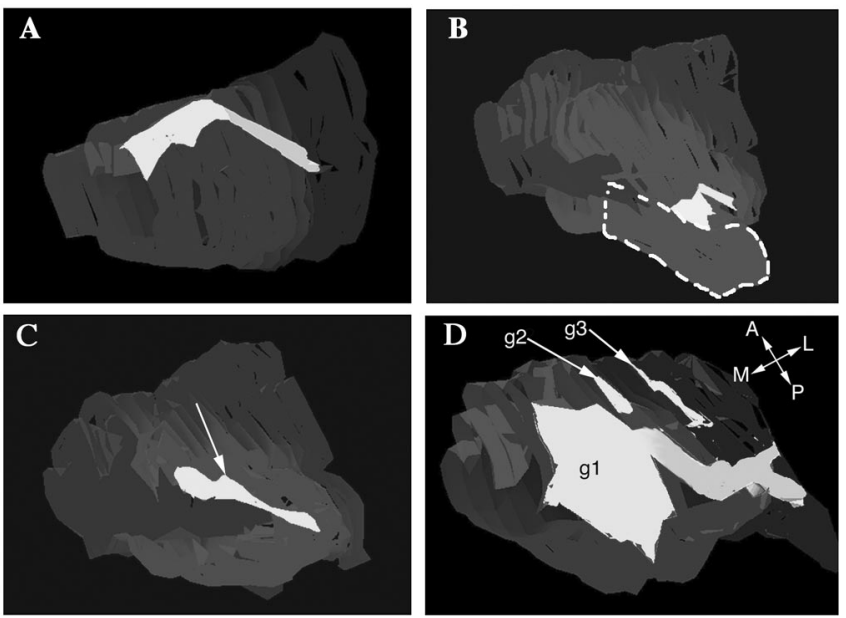

Figure 5. Three-dimensional reconstructions of $m a t h 1^{\beta-G a l / \beta-G a l} \leftrightarrow+/+$ chimeric cerebella. In all of the reconstructions, EGLs containing granule cells are gray, whereas areas without granule cells in the EGL are white. $A$, In this P0 chimera, the agranular EGL traverses several lobules in the posterior cerebellum, beginning at the midline and ending in the initial segments of the hemisphere. $B$, In this P5 chimera, the agranular zone of the EGL is located to a circumspect area starting medially in lobule VIII and progressing to the interface of the vermis and hemisphere. Lobule VIII of this brain is abnormally extended in the posterior direction (outlined in white dashed line), and this extension starts at the point that the agranular EGL starts. C, In this P5 chimera, the agranular region is located in the posterior cerebellum, extending laterally along the superior surface of lobule 6 . The lobule containing the agranular EGL (white arrow) is shorter than the same lobule in control brains. D, In this P5 cerebellum, three distinct areas of the EGL are agranular. The largest gap (g1) traverses the entire medial to lateral extent of the cerebellum, without gaps. In the medial cerebellum, the agranular area encompasses much of the posterior cerebellum, whereas in the hemisphere the agranular region is more discrete. Two smaller agranular regions were seen in this brain that were oriented in the anterior-to-posterior axis. $A$, Anterior; $P$, posterior; $M$, medial; L, lateral.
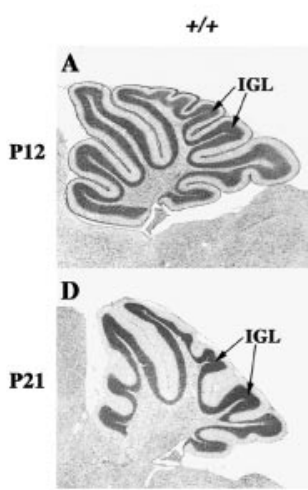

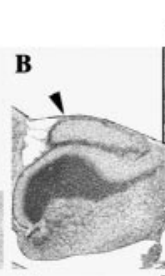

E

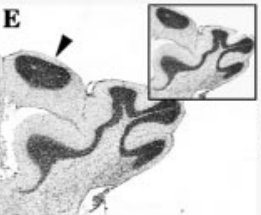

$\operatorname{math1}^{\beta-g a t / \beta-g a l}<->+1+$

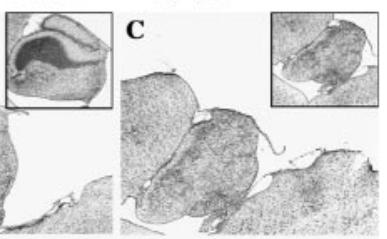

F

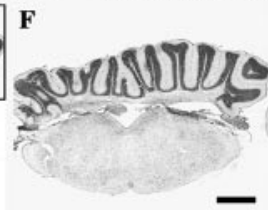

Figure 6. math $^{\beta-G a l / \beta \text {-Gal }} \leftrightarrow+/+$ chimeras demonstrate severe foliation defects in the $\mathrm{P} 12$ and $\mathrm{P} 21$ cerebellum. Sagittal view of $\mathrm{P} 12+/+(A)$ and math $^{\beta-G a l / \beta-G a l} \leftrightarrow+/+(B, C)$ medial cerebella and P21 $+/+(D)$ and $\operatorname{math}_{1}{ }^{\beta-G a l / \beta-G a l} \leftrightarrow+/+(E)$ lateral cerebella, and coronal view of P21 math $1^{\beta-G a l / \beta \text {-Gal }} \leftrightarrow+/+$ cerebellum $(F)$ stained with cresyl violet. In all chimeric animals $(B, C, E, F)$, foliation is disrupted compared with wild-type cerebella in $A$ and $D$. $\ln C$, the absence of foliation is associated with the almost complete lack of an IGL. In $B$ and $E$, folia (arrowheads) appear to have collapsed inward, and in Fthere is hyperfoliation. In all cases, there is a reduction in the size of the cerebellum compared with the wild type (insets: compare $B,($ with $A$; compare $E$ with $D$ ). Scale bar: $A, D, F$, insets, $600 \mu \mathrm{m} ; B, C, E, 300 \mu \mathrm{m}$.

Math1/LacZ-positive cells. We found that only GFAP colocalized with the $\beta$-gal-positive cells (Fig. 8 ). However, there were $\beta$-galpositive cells that were neither GFAP nor NeuN positive. This does not rule out the possibility that these cells may be one or more of the cerebellar interneurons that do not label with NeuN (Weyer and Schilling, 2003).

Because math $1^{\beta-G a l / \beta-G a l}$ cells were evidently absent in the EGL

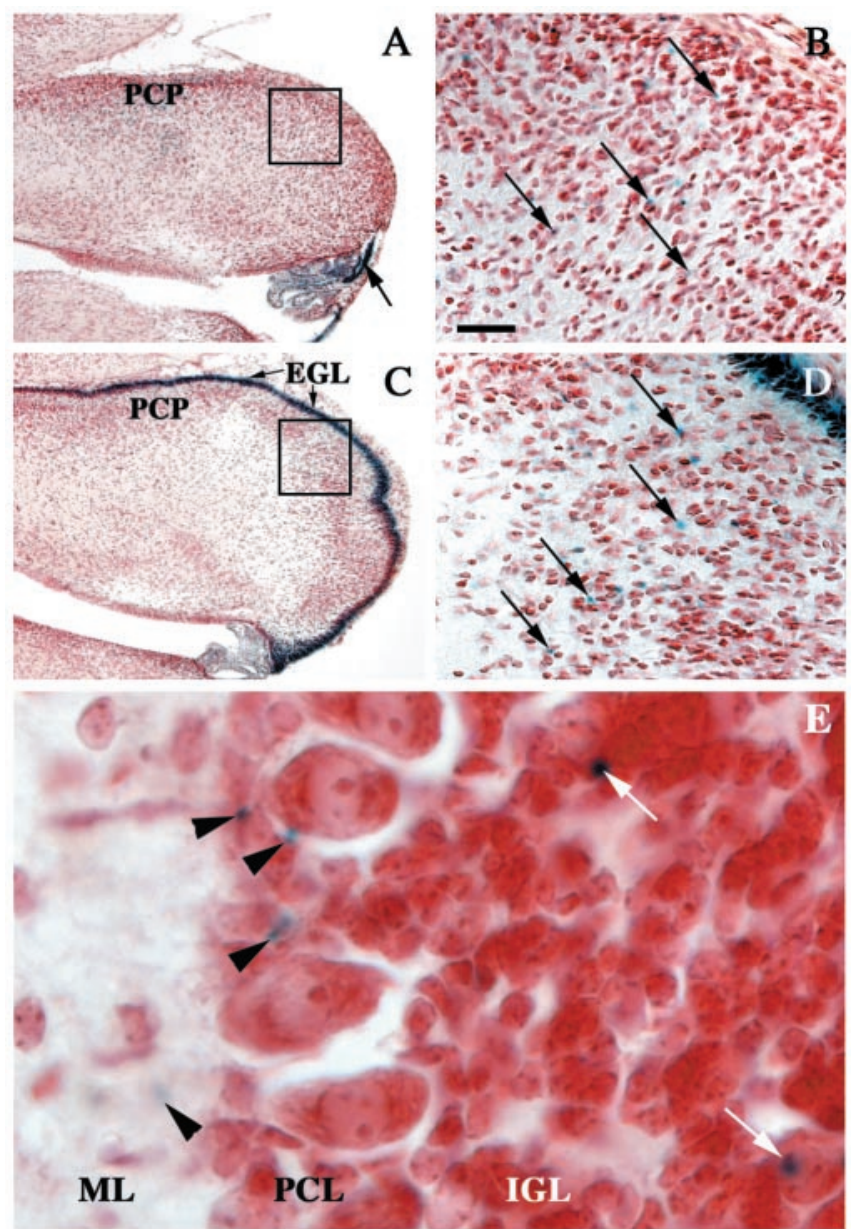

Figure 7. $m a t h 1^{\beta-G a l / \beta-G a l}$ granule cell precursors are not generated in the $m a t h 1^{\beta-G a l / \beta-G a l}$ $\leftrightarrow+/+$ cerebellum. Coronal view of a P0 math $7^{\beta-\text { Gal } \beta \text {-Gal }} \leftrightarrow+/+(A, B)$ and math ${ }^{\beta-G a l /+}$ $\leftrightarrow+/+(C, D)$ cerebellum and P12 math $7^{\beta-\text { Gal } \beta \text {-Gal } \leftrightarrow}+/+$ cerebellum $(E)$ reacted for $\beta$-gal activity and counterstained with neutral red. In the high percentage math ${ }^{\beta-G a l / \beta \text {-Gal }}$ cerebellum in $A$ and $B$, there is no discernable EGL present compared with the EGL in a high percentage math $1 \beta^{- \text {Gal/ }+}$ chimeric cerebellum in $C$ and $D$. However, $m a t h 1^{\beta \text {-Gal/ } \beta \text {-Gal }}$ blue cells (arrows) are seen in the medullary vellum and choroids plexus in $A$ and deep to and within the PCP in B. Math1/lacZ-positive blue cells are found in the same location in the math $1^{\beta-G a l /+} \leftrightarrow$ $+/+$ cerebellum in $D . \operatorname{In} E$, the P12 math $1^{\beta-\text { Gal } \beta \text {-Gal }} \leftrightarrow+/+$ cerebellum, math $^{\beta-\text { Gal } / \beta \text {-Gal }}$ blue cells (arrowheads) are found within the molecular layer (ML) and adjacent to Purkinje cells.

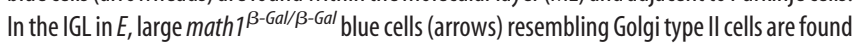
among the much smaller +/+ red granule cells. Scale bar: $E, 15 \mu \mathrm{m} ; B, D, 30 \mu \mathrm{m} ; A, C, 180 \mu \mathrm{m}$.

of mutant chimeras, we wanted to confirm that the cells present in the EGL were of wild-type origin. DNA in situ hybridization for the globin transgene was performed to identify wild-type EGL cells in math $1^{\beta-G a l / \beta-G a l} \leftrightarrow$ GTO chimeras (see Materials and Methods). In math $1^{\beta-G a l / \beta-G a l} \leftrightarrow$ GTO chimeras, all cells within the EGL were labeled with the wild-type cell marker confirming the absence of mutant granule cell neuroblasts in the math1 null chimeric cerebellum (Fig. 9A-C).

To determine the extent of chimerism, we measured the area of the EGL in P0 and P5 chimeric and control cerebella. There was no difference in EGL area between nonmutant chimeras and wild-type controls, and these values were considered as a single control group. We found there was a reduction in the area of the EGL in all math $1^{\beta-G a l / \beta-G a l}$ chimeras compared with controls ( $\mathrm{Ta}$ ble 2). We then examined the cerebellar area of mutant chimeras and controls. We found that in all math1 null mutant chimeras with large decreases in EGL area there was a concomitant reduc- 

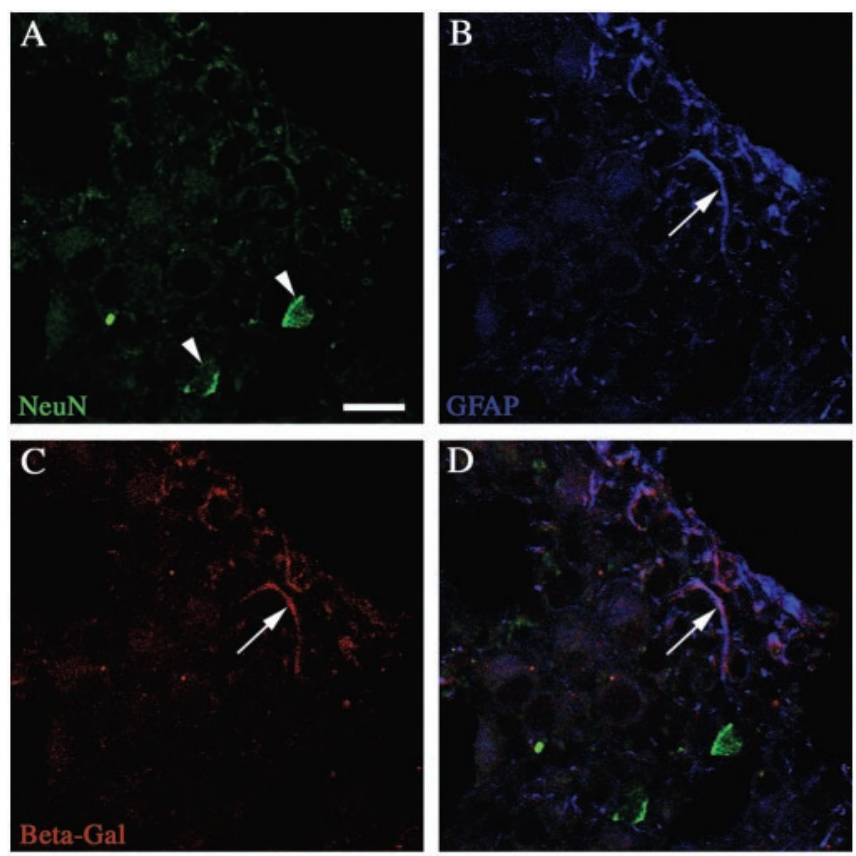

Figure 8. Some Math1/LacZ-positive cells in the P12 math $1^{\beta-G a l / \beta-G a l} \leftrightarrow+/+$ cerebellum are also GFAP positive. $A-D$, Sagittal view of the agranular P12 math $1^{\beta-G a l / \beta-G a l} \leftrightarrow+/+$ cerebellum in Figure $10 B$, immunostained for the neuronal marker $\operatorname{NeuN}(A$, arrowheads), the glial marker GFAP ( $B$, arrow), and the Math1/LacZ + marker $\beta$-gal ( $C$, arrow). In the merged image $(D)$, most of the $\beta$-gal-immunopositive cells were also positive for GFAP. Scale bar, $30 \mu \mathrm{m}$.
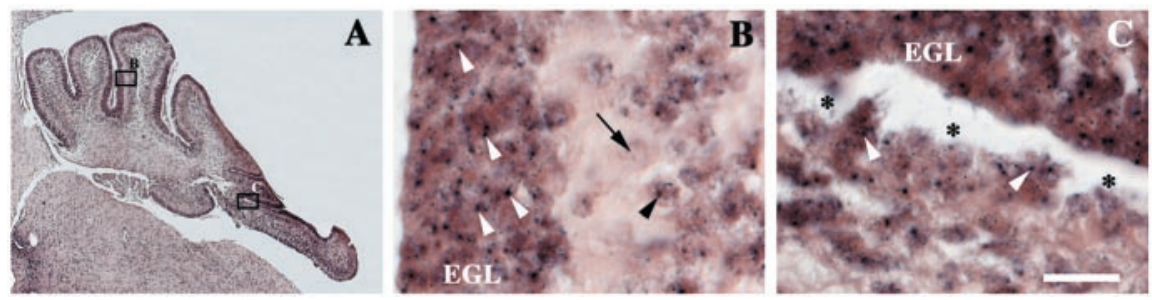

Figure 9. Only $+/+$ cells colonize the $\mathrm{EGL}$ in the math $1^{\beta-G a l / \beta-G a l} \leftrightarrow+/+$ cerebellum. $A-C$, Sagittal view of a P5 math $1^{\beta-G a l / \beta-G a l} \leftrightarrow+/+$ cerebellum probed for the presence of the Globin transgene present in the wild-type cells of the chimeric cerebellum. In both normal $(B)$ and disrupted ( $C$ regions (asterisks) of the chimeric cerebellum, the EGL contains only labeled $+/+$ granule cell neuroblasts (white arrowheads), whereas both $+/+$ (black arrowhead) and math ${ }^{\beta \text {-Gal } \beta \text {-Gal }}$ (arrow) Purkinje cells are found. Scale bar: $A, 378 \mu \mathrm{m} ; B, C, 30 \mu \mathrm{m}$.

tion in cerebellar area (Table 2). However, in some mutant chimeras with only small disruptions in the EGL there was an increase in cerebellar area compared with controls (Table 2). In all cases, the increase in cerebellar area was associated with hyperfoliation, hyperextension, or both of one or more lobules.

\section{Purkinje cell positioning in the chimeric cerebellum}

To determine how the gaps in the math $1^{\beta-G a l / \beta-G a l}$ chimeric EGL affect the underlying Purkinje cells, we examined Purkinje cell positioning in all chimeras using an antibody against the Purkinje cell marker calbindin. In the P0 and P5 wild-type cerebellum, Purkinje cells were arranged in a several cell-thick Purkinje cell plate (PCP) below the EGL. In the P0 and P5 mutant chimeric cerebellum, a well defined PCP was evident in all chimeras examined. This finding was not surprising, because we have shown that the PCP forms even in the complete absence of the EGL in the math $1^{\beta-G a l / \beta-G a l}$ P0 cerebellum (Jensen et al., 2002). In the P12 and P21 wild-type cerebellum, coinciding with the expansion of the cerebellum and increased foliation, Purkinje cells were aligned in a single layer of cells located between the molecular layer above and the underlying IGL (Fig. 10A,C). In all P12 and P21 mutant chimeras, the Purkinje cell layer was disrupted in regions where the EGL and IGL were disrupted. In these disrupted regions, Purkinje cells were in unorganized clusters (Fig. $10 \mathrm{D}$, inset). Areas immediately adjacent to the disrupted region, where the EGL and IGL were intact, exhibited normal trilaminar cortical structure (Fig. 10D). In addition, in chimeras in which the most anterior EGL and IGL were disrupted, there were ectopic Purkinje cells found within the inferior colliculus (Fig. $10 B, E$, insets). This ectopic population was not found in mutant chimeras in which the most anterior EGL and IGL were intact (Fig. 10D). Thus, the laminar structure of Purkinje cells is disrupted in all regions where the EGL is absent. In regions where a large portion of the EGL is absent (e.g., an entire lobe of the cerebellum), Purkinje cells form unorganized clusters below the pial surface. These findings add to the expanding literature on the critical role that granule cells play in the registration of Purkinje cells into a well defined layer (Jensen et al., 2002).

\section{Discussion}

In this study, we have examined the development of the ARL in the math1 null mutant and the development of the cerebellum in math1 null chimeras. We show that, at early stages of cerebellar development, the ARL is composed of a heterogeneous population of cells: the math1-dependent granule cells and the math1independent cells found in the heterozygous and homozygous mutant cerebellum. We also demonstrate that math $1^{\beta-G a l / \beta-G a l}$ granule cell neuroblasts do not populate the math $1^{\beta-G a l / \beta-G a l}$ $\leftrightarrow+/+$ cerebellum and that wild-type cells are unable to compensate for the loss of mutant cells. Finally, the colonization of the EGL by wild-type cells and acellular gaps provide evidence that granule cell neuroblasts not only undergo active migration but are spatially specified in the ARL.

The relatively normal cell proliferation that we observe in the math $1^{\beta-G a l / \beta-G a l}$ ARL is likely caused by the presence of Math1/lacZ-positive cells in the ARL that do not give rise to granule cells. The migration of these cells from the ARL helps explain the gradual diminution of the ARL population of cells over time. The presence of migrating cells from the ARL in the math1 null cerebellum was not surprising in light of recent cell lineage studies in the chick and zebrafish (Wingate and Hatten, 1999; Koster and Fraser, 2001; Lin et al., 2001). These authors have found evidence for the emigration of cells from the ARL to areas outside of the cerebellum. What was surprising was our finding that some of these Math1-positive cells that originate from the ARL populate the cerebellum. The origins of all but the principal neurons of the cerebellum have been a subject of much debate (Hallonet et al., 1990; Alvarez Otero et al., 1993; Ryder and Cepko, 1994; Alder et al., 1996; Zhang and Goldman, 1996). The majority of studies addressing this issue finds that the EGL only gives rise to granule cells. Based on this finding, for example, it has been presumed that the cerebellar interneurons are derived from the primary cerebellar neuroepithelium. These studies, however, examined relatively late times during development and did not rule out an initial origin of these cells from the ARL. In fact, in light of our current findings, it is also 
Table 2. EGL and cerebellar area in P0 and P5 math1 $1^{\beta-g a l / \beta-g a l} \leftrightarrow+/+$ chimeras and controls

\begin{tabular}{|c|c|c|c|c|}
\hline Age & Chimera & Genotype & ${\text { EGL } \text { area }^{a}\left(\mu \mathrm{m}^{2}\right)}^{2}$ & Cerebellum area $^{a}\left(\mu \mathrm{m}^{2}\right)$ \\
\hline P5 & & $\operatorname{math}^{+/+}$ & 194705 & 1239518 \\
\hline P5 & & ICR & 184015 & 1149068 \\
\hline P5 & 090700K & math $1^{\beta-g a l / \beta-g a l} \leftrightarrow \mathrm{ICR}$ & 65845 & 595783 \\
\hline P5 & 090700A & $\operatorname{math}^{\beta-g a l / \beta-g a l} \leftrightarrow \mathrm{ICR}$ & 85515 & 506948 \\
\hline P5 & 090700M & $\operatorname{math} 1^{\beta-g a l / \beta-g a l} \leftrightarrow \mathrm{ICR}$ & 121622 & 1243073 \\
\hline P5 & $090700 G$ & Math $1^{\beta-g a l / \beta-g a l} \leftrightarrow \mathrm{ICR}$ & 136389 & 1253508 \\
\hline P5 & & Math1 $1^{\beta-g a l /+}$ or ${ }^{+/+} \leftrightarrow \mathrm{ICR}$ & $184477^{b}(164213-213105)$ & $1148023^{b}(1013108-1332086)$ \\
\hline P0 & & math $1^{+/+}$ & 59343 & 524207 \\
\hline PO & & Balb/c & 61298 & 532759 \\
\hline PO & 080899H & math $1^{\beta-g a l / \beta-g a l} \leftrightarrow$ Balb/ $/{ }^{J}$ & 26285 & 426604 \\
\hline PO & 080899E & $\begin{array}{l}\operatorname{math} 1^{\beta-g a l / \beta-g a l} \leftrightarrow \text { Balb/c } \\
\text { Math1 } 1^{\beta-g a l /+} \text { or }{ }^{+/+} \leftrightarrow\end{array}$ & 44028 & 507886 \\
\hline PO & & Balb/c & $59296^{b}(55081-63605)$ & $539310^{b}(516805-572824)$ \\
\hline
\end{tabular}

${ }^{a}$ Mean area of EGL and cerebellum calculated for three nonconsecutive sections.

${ }^{b}$ Mean area of EGL and cerebellum calculated for three nonconsecutive sections of $n=5$ animals within each group. The range of mean for individual animals is in parentheses.

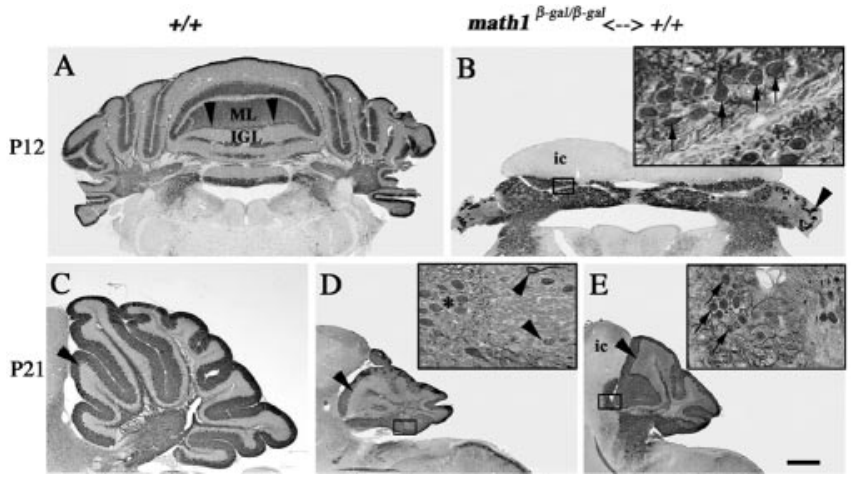

Figure 10. Purkinje cell lamination defects are present in regions where granule cells are deficient in the math $1^{\beta-G a l / \beta \text {-Gal }} \leftrightarrow$ $+/+$ cerebellum. Coronal view of a P12 $+/+(A)$ and $m a t h 1^{\beta-G a l / \beta-G a l} \leftrightarrow+/+(B)$ cerebellum and sagittal view of a P21 $+/+(C)$ and math $1^{\beta-G a l / \beta-G a l} \leftrightarrow+/+(D, E)$ cerebellum immunostained for the Purkinje cell marker calbindin and counterstained with cresyl violet. In the P12 $(A)$ and P21 $(C)+1+$ cerebellum, Purkinje cells (arrowheads) are aligned in a single layer between the molecular layer $(\mathrm{ML})$ and the IGL. In all chimeras $(B, D, E)$, the Purkinje cell layer is disrupted where the granule cell layer is disrupted. Where the granule cell layer is absent, Purkinje cells (asterisk) are in unorganized clusters ( $D$, inset). In adjacent regions where the granule cell layer is intact, Purkinje cells (arrowhead) are aligned in a single layer. When the granule cell layer is disrupted in the anterior cerebellum $(B, E)$, Purkinje cells (arrows) migrate into the inferior colliculus (ic). Scale bar: $A-E, 400$ $\mu \mathrm{m}$; insets in $D, E, 30 \mu \mathrm{m}$; inset in $B, 15 \mu \mathrm{m}$.

possible that at least some of these cells (e.g., an undetermined number of Bergmann glia and Golgi type II cells) actually first originate from the ARL, from the Math1-positive, independent cell population. A more detailed analysis of the origins and migratory path(s) of these cells is warranted.

In the chimeric cerebellum, math 1 null cells do not colonize the EGL. This indicates a completely cell-autonomous action of the math 1 gene in granule cell development. Moreover, based on the developmental analysis of the math1 null ARL, it appears that granule cell neuroblasts are never generated. Although it may be axiomatic that transcription factors act intrinsic to cell function, the downstream effects of transcriptional activation or repression often are translated through other cells. There are many such examples of non-cell autonomous actions of transcription factors during development (Rhinn et al., 1999; Kitajima, 2000; Weinhold et al., 2000; Cui et al., 2003). Likewise, whereas studies of the Math1 knock-out mouse indicates that Math1 expression is intrinsic to, and critical for, inner hair cell development (Bermingham et al., 1999), preliminary studies of the math1 null chimera (K. Hamre, personal communication) have indicated that Math1 null inner hair cells can exist in a chimera, suggesting a non-cell autonomous action of the math1 gene in inner hair cell determination. In the cerebellum, a similar feed-forward or feedback mechanism could exist in which extrinsic elements can induce math 1 null cells to enter into the granule cell lineage. This clearly is not the case in any of the chimeras studied in the present research. Thus, Math1 is a vital molecule in the granule cell lineage.

Other genes have been proposed to play critical roles in granule cell lineage based on their expression pattern within the ARL and granule cell precursor population within the EGL (Aruga et al., 1994; Yang et al., 1996). However, targeted deletion of these genes have resulted in no or only partial loss of granule cell neuroblasts (Aruga et al., 1998; Yang et al., 1999). To date, math1 is the only example of a gene that is expressed within the ARL and that results in the complete loss of granule cells when disrupted (Ben-Arie et al., 1997).

One fascinating outcome in math1null chimeras is that there is no obvious compensation by wild-type granule cells. This situation is in contrast to other instances in which granule cells are eliminated from the EGL by X-irradiation or chemical insult to the postnatal cerebellum. In these experimental conditions, there is an amazing capacity for the regeneration of the granule cell population (Shimada and Langman, 1970a,b; Altman, 1973; Jones and Gardner, 1976; Yu, 1979; Lovell et al., 1980; Chen and Hillman, 1986, 1988; Altman and Bayer, 1997; Doughty et al., 1998). However, the extent of this regeneration is dependent on when the insult occurs and the degree of damage to the EGL. For example, administration of the antimitotic agent MAM within $24 \mathrm{hr}$ of birth results in extensive damage to the EGL with only limited regeneration (Chen and Hillman, 1988). One explanation for the apparent lack of EGL regeneration in the math1 null is that Math1 functions at a developmental time when the progenitor cell population is determined, and each of these cells has a set proliferative capacity. Thus, when math 1 null members of the progenitor pool are eliminated there is an irretrievable loss of clonal sets of granule cells. How this interpretation sits with the previous finding in the meander tail chimera is an area for additional exploration. In the meander tail mutant mouse, there is a near-total loss of anterior lobe granule cells that can be 
seen as early as E13-E15 (Napieralski and Eisenman, 1993; Hamre and Goldowitz, 1997). However, in the meander tail chimera there is a dramatic increase in the production of wild-type granule cells in the anterior cerebellum (Hamre and Goldowitz, 1997). We expect that the identification of the meander tail gene and its expression pattern will help to solve this apparent incongruity in which there is compensation by wild-type granule cells in meander tail, but not math1 null, chimeras.

The loss of math1 null granule cell neuroblasts in the math $1^{\beta-G a l / \beta-G a l} \leftrightarrow+/+$ brain results in regions of the EGL devoid of neuroblasts. Interestingly, in some chimeras these regions devoid of neuroblasts are noncontiguous. These results suggest that the EGL is actively populated by waves of neuroblasts that leave the ARL at discrete intervals with a set destination along the surface of the cerebellum. Thus, in the math $1^{\beta-G a l / \beta-G a l} \leftrightarrow+/+$ cerebellum, the EGL is a patchwork of wild-type cells and empty spaces, with the spaces presumed to be regions that should have been colonized by sets of math 1 null granule cell neuroblasts. This suggestion of the migratory dynamics of EGL neuroblasts is similar to the observations of an active and orderly process in the migration of cerebellar ARL cells in the explanted chick cerebellum (Wingate and Hatten, 1999; Gilthorpe et al., 2002). The observations of Wingate and Hatten (1999) led to the prediction "that subsequent waves of migrating cells stop at successively more proximal points on the surface of the anlage, perhaps inhibited from further migration by the accumulation of older precusors." From the present results, we would agree with the initial premise of their prediction, however, would note that the vacant regions of the EGL in chimeras would not be evidence for an inhibitory mechanism but, rather, would suggest a predetermined spatial address for cohorts of EGL neuroblasts. This spatial address is most likely encoded temporally and is consonant with more recent finding that demonstrates a temporal organization of two different precursors in the chick ARL (Gilthorpe et al., 2002).

In conclusion, the current study demonstrates a vital, cellautonomous role for Math1 in the granule cell lineage from the onset of the appearance of granule cell precursors in the ARL. In addition, the analysis of the math1 null chimeric cerebellum provides new insights into the temporal and spatial mechanisms that drive the migration of granule cell neuroblasts in the formation of the EGL. Finally, the view that the ARL gives rise to a homogeneous population of cells is challenged by our finding that multiple cell types coexist within, and migrate from, the ARL.

\section{References}

Akazawa C, Ishibashi M, Shimizu C, Nakanishi S, Kageyama R (1995) A mammalian helix-loop-helix factor structurally related to the product of Drosophila proneural gene atonal is a positive transcriptional regulator expressed in the developing nervous system. J Biol Chem 270:8730-8738.

Alder J, Cho NK, Hatten ME (1996) Embryonic precursor cells from the rhombic lip are specified to a cerebellar granule neuron identity. Neuron 17:389-399.

Altman J (1973) Experimental reorganization of the cerebellar cortex. III. Regeneration of the external germinal layer and granule cell ectopia. J Comp Neurol 149:153-180.

Altman J, Bayer SA (1997) Development of the cerebellar system: in relation to its evolution, structure, and functions. Boca Raton, FL: CRC.

Alvarez Otero R, Sotelo C, Alvarado-Mallart RM (1993) Chick/quail chimeras with partial cerebellar grafts: an analysis of the origin and migration of cerebellar cells. J Comp Neurol 333:597-615.

Aruga J, Yokota N, Hashimoto M, Furuichi T, Fukuda M, Mikoshiba K (1994) A novel zinc finger protein, zic, is involved in neurogenesis, especially in the cell lineage of cerebellar granule cells. J Neurochem 63:1880-1890.

Aruga J, Minowa O, Yaginuma H, Kuno J, Nagai T, Noda T, Mikoshiba K
(1998) Mouse Zic1 is involved in cerebellar development. J Neurosci 18:284-293.

Ben-Arie N, McCall AE, Berkman S, Eichele G, Bellen H, Zoghbi HY (1996) Evolutionary conservation of sequence and expression of the bHLH protein Atonal suggests a conserved role in neurogenesis. Hum Mol Genet 5:1207-1216.

Ben-Arie N, Bellen HJ, Armstrong DL, McCall AE, Gordadze PR, Guo Q, Matzuk MM, Zoghbi HY (1997) Math1 is essential for genesis of cerebellar granule neurons. Nature 390:169-172.

Ben-Arie N, Hassan BA, Bermingham NA, Malicki DM, Armstrong D, Matzuk M, Bellen HJ, Zoghbi HY (2000) Functional conservation of atonal and Math1 in the CNS and PNS. Development 127:1039-1048.

Bermingham NA. Hassan BA, Price SD, Vollrath MA, Ben-Arie N, Eatock RA, Bellen HJ, Lysakowski A, Zoghbi HY (1999) Math1: an essential gene for the generation of inner ear hair cells. Science 284:1837-1841.

Chen S, Hillman DE (1986) Selective ablation of neurons by methylazoxymethanol during pre- and postnatal brain development. Exp Neurol 94:103-119.

Chen S, Hillman DE (1988) Developmental factors related to abnormal cerebellar foliation induced by methylazoxymethanol acetate (MAM). Brain Res 468:201-212.

Cui S, Schwartz L, Quaggin SE (2003) Pod1 is required in stromal cells for glomerulogenesis. Dev Dyn 226:512-522.

Doughty ML, Delhaye-Bouchaud N, Mariani J (1998) Quantitative analysis of cerebellar lobulation in normal and agranular rats. J Comp Neurol 399:306-320.

Friedrich G, Soriano P (1991) Promoter traps in embryonic stem cells: a genetic screen to identify and mutate developmental genes in mice. Genes Dev 5:1513-1523.

Gilthorpe JD, Papantoniou EK, Chedotal A, Lumsden A, Wingate RJ (2002) The migration of cerebellar rhombic lip derivatives. Development 129:4719-4728.

Goldowitz D (1989) The weaver granuloprival phenotype is due to intrinsic action of the mutant locus in granule cells: evidence from homozygous weaver chimeras. Neuron 2:1565-1575.

Goldowitz D, Mullen RJ (1982) Granule cell as a site of gene action in the weaver mouse cerebellum: evidence from heterozygous mutant chimeras. J Neurosci 2:1474-1485.

Hallonet ME, Teillet MA, Le Douarin NM (1990) A new approach to the development of the cerebellum provided by the quail-chick marker system. Development 108:19-31.

Hamre KM, Goldowitz D (1997) meander tail acts intrinsic to granule cell precursors to disrupt cerebellar development: analysis of meander tail chimeric mice. Development 124:4201-4212.

Helms AW, Johnson JE (1998) Progenitors of dorsal commissural interneurons are defined by MATH1 expression. Development 125:919-928.

Helms AW, Abney AL, Ben-Arie N, Zoghbi HY, Johnson JE (2000) Autoregulation and multiple enhancers control Math1 expression in the developing nervous system. Development 127:1185-1196.

Jensen P, Zoghbi HY, Goldowitz D (2002) Dissection of the cellular and molecular events that position cerebellar Purkinje cells: a study of the math1 null-mutant mouse. J Neurosci 22:8110-8116.

Jiao Y, Sun Z, Lee T, Fusco FR, Kimble TD, Meade CA, Cuthbertson S, Reiner A (1999) A simple and sensitive antigen retrieval method for freefloating and slide-mounted tissue sections. J Neurosci Methods 93:149-162.

Jones MZ, Gardner E (1976) Pathogenesis of methylazoxymethanolinduced lesions in the postnatal mouse cerebellum. J Neuropathol Exp Neurol 35:413-444.

Kitajima S, Takagi A, Inoue T, Saga Y (2000) MesP1 and MesP2 are essential for the development of cardiac mesoderm. Development 127:3215-3226.

Konigsmark BW (1970) Methods for the counting of neurons. In: Contemporary research methods in neuroanatomy (Nauta WJH, Ebbesson SOE, eds), pp 315-340. New York: Springer.

Koster RW, Fraser SE (2001) Direct imaging of in vivo neuronal migration in the developing cerebellum. Curr Biol 11:1858-1863.

Lin JC, Cai L, Cepko CL (2001) The external granule layer of the developing chick cerebellum generates granule cells and cells of the isthmus and rostral hindbrain. J Neurosci 21:159-168.

Lo CW, Coulling M, Kirby C (1987) Tracking of mouse cell lineage using microinjected DNA sequences: analyses using genomic Southern blotting and tissue-section in situ hybridizations. Differentiation 35:37-44. 
Louvi A, Alexandre P, Metin C, Wurst W, Wassef M (2003) The isthmic neuroepithelium is essential for cerebellar midline fusion. Development 130:5319-5330.

Lovell KL, Goetting MG, Jones MZ (1980) Regeneration in the cerebellum following methylazoxymethanol-induced destruction of the external germinal layer. Morphological and biochemical studies. Dev Neurosci 3:128-139.

Miale IL, Sidman RL (1961) An autoradiographic analysis of histogenesis in the mouse cerebellum. Exp Neurol 4:277-296.

Napieralski JA, Eisenman LM (1993) Developmental analysis of the external granular layer in the meander tail mutant mouse: do cerebellar microneurons have independent progenitors? Dev Dyn 197:244-254.

Rhinn M, Dierich A, Le Meur M, Ang S (1999) Cell autonomous and noncell autonomous functions of Otx2 in patterning the rostral brain. Development 126:4295-4304.

Rigby PW, Dieckmann M, Rhodes C, Berg P (1977) Labeling deoxyribonucleic acid to high specific activity in vitro by nick translation with DNA polymerase I. J Mol Biol 113:237-251.

Ryder EF, Cepko CL (1994) Migration patterns of clonally related granule cells and their progenitors in the developing chick cerebellum. Neuron 12:1011-1028.

Shimada M, Langman J (1970a) Repair of the external granular layer after postnatal treatment with 5-fluorodeoxyuridine. Am J Anat 129:247-259.
Shimada M, Langman J (1970b) Repair of the external granular layer of the hamster cerebellum after prenatal and postnatal administration of methylazoxymethanol. Teratology 3:119-133.

Weinhold B, Schratt G, Arsenian S, Berger J, Kamino K, Schwarz H, Ruther U, Nordheim A (2000) Srf(-/-) ES cells display non-cell-autonomous impairment in mesodermal differentiation. EMBO J 19:5835-5844.

Weyer A, Schilling K (2003) Developmental and cell type-specific expression of the neuronal marker NeuN in the murine cerebellum. J Neurosci Res 73:400-409.

Wingate RJ, Hatten ME (1999) The role of the rhombic lip in avian cerebellum development. Development 126:4395-4404.

Yang XW, Zhong R, Heintz N (1996) Granule cell specification in the developing mouse brain as defined by expression of the zinc finger transcription factor RU49. Development 122:555-566.

Yang XW, Wynder C, Doughty ML, Heintz N (1999) BAC-mediated genedosage analysis reveals a role for Ziprol (Ru49/Zfp38) in progenitor cell proliferation in cerebellum and skin. Nat Genet 22:327-335.

Yu WH (1979) Restitution of bromodeoxyuridine-induced changes in cerebellar development. Neuropathol Appl Neurobiol 5:41-48.

Zhang L, Goldman JE (1996) Generation of cerebellar interneurons from dividing progenitors in white matter. Neuron 16:47-54. 